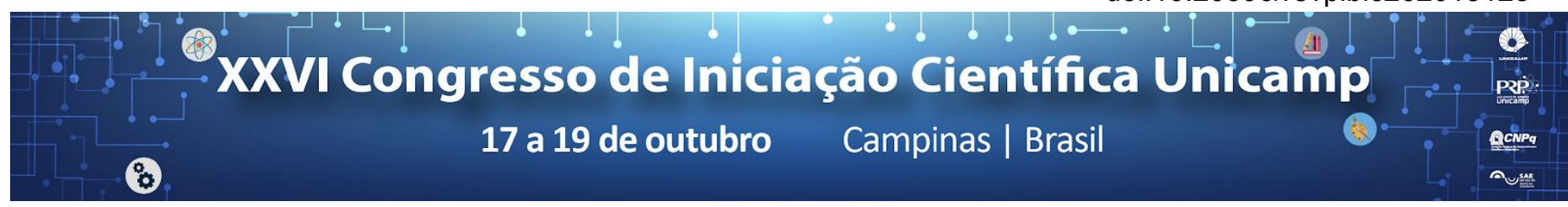

\title{
Structural hypothalamic abnormalities in amyotrophic lateral sclerosis (ALS)
}

\author{
Ana Luisa C. C. Hernández, Thiago J. R. Junqueira, Marcondes C. França Jr.
}

\begin{abstract}
ALS concomitantly affects the upper and lower motor neurons progressively, and is characterized by early pronounced weight loss. Our hypothesis is that this symptom is caused by damages in the hypothalamus, region that exerts an essential role in the metabolic control. We used MRI and, through Multi-Atlas T1 segmentation, quantified the volume of the hypothalamus in a group of patients $(n=105)$ and controls $(n=113)$. There was no significant difference in the hypothalamic volume between groups. In contrast, we found atrophy in left-sided Claustrum $(p=0.0002)$ and Posterior Basal Forebrain $(p=0.02)$ in the ALS group, regions also associated with metabolic control, reinforcing the hypothesis that metabolic dysregulation underlies ALS-related cachexia.
\end{abstract}

\section{Key words:}

Amyotrophic Lateral Sclerosis, Neuroimaging, Metabolism .

\section{Introduction}

ALS is the most relevant motor neuron disease in adults, which concomitantly affects the upper and lower neurons progressively. The hypothalamus is the center of hunger and satiety, it also regulates ANS and the melanocortin system, therefore, it is an important metabolic control center. ALS is characterized by marked weight loss, which is classically attributed to dysphagia and muscle atrophy. However, new studies indicate that there is an abnormal metabolic control in ALS caused by hypothalamic damage in the disease. Experimental studies have shown neuronal loss in this region, but few studies have evaluated this damage in vivo.

\section{Results and Discussion}

We recruited a group of patients $(n=105)$, with a diagnosis of ALS, and controls $(n=113)$, who underwent 3T MRI of the brain. The images were segmented through Multi-Atlas T1 and the labels matching the regions of interest were selected. Data analysis was done through generalized linear model, having as covariates total intracranial volume, age, sex and clinical parameters (age, duration of disease and ALSFRS score). Values of $p<0.05$ were considered significant.

Mean age of patients was 54 years and there were 55 men. Mean ALSFRS score and disease duration were 32 and 3,8 years, respectively. In the volumetric analyses, there were no significant differences between patients and controls regarding Hypothalamus, Mammillary Body, Nucleus Accumbens, Anterior Basal Forebrain, and right-sided Posterior Basal Forebrain and Claustrum volumes. In contrast, we found left-sided Claustrum and
Posterior Basal Forebrain atrophy in the ALS group. There was no significant correlation between clinical parameters. However, by using an automated tool, the values may have been distorted, requiring more precise segmentation to confirm the results.

Table 1. Comparison between values from groups ELA and control.

\begin{tabular}{|c|c|c|c|c|c|}
\hline Estrutura & ELA & & Controle & & $\mathrm{p}$ valor \\
\hline & Média & DP & Média & DP & \\
\hline Claustrum D & 330.59 & 65.39 & 423.28 & 58.38 & 0.05 \\
\hline Claustrum E & 289.3 & 61.26 & 379.78 & 50.21 & 0.00 \\
\hline Corpo Mamilar D & 75.65 & 18.55 & 90.07 & 14.51 & 0.37 \\
\hline Corpo Mamilar E & 64.03 & 14.08 & 80.66 & 13.58 & 0.76 \\
\hline Hipotálamo D & 530.79 & 107.78 & 665.73 & 73.84 & 0.67 \\
\hline Hipotálamo E & 443.36 & 90.82 & 558.26 & 74.09 & 0.52 \\
\hline Núcleo Accumbens D & 596.3 & 121.26 & 765.37 & 116.24 & 0.17 \\
\hline Núcleo Accumbens E & 497.95 & 103.79 & 646.06 & 104.69 & 0.25 \\
\hline Prosencéfalo Basal Anterior D & 229.03 & 54.05 & 289.5 & 51.62 & 0.25 \\
\hline Prosencéfalo Basal Anterior E & 237.14 & 57.59 & 297.08 & 56.77 & 0.20 \\
\hline Prosencéfalo Basal Posterior D & 998.03 & 199.27 & 1267.09 & 145.37 & 0.08 \\
\hline Prosencéfalo Basal Posterior E & 1134.5 & 225.18 & 1451.19 & 156.94 & 0.02 \\
\hline
\end{tabular}

Although there was no significant atrophy in the hypothalamus, nearby areas also involved in metabolic control were found abnormal in ALS. This reinforces the hypothesis that metabolic dysregulation underlies ALS-related cachexia.

\section{Acknowledgement}

This project was sponsored by CNPq.

Vercruysse, P., et al. Alterations in the hypothalamic melanocortin pathway in amyotrophic lateral sclerosis. Brain. 2016; 139(4): 1106-1122.

Gorges M, et al. Hypothalamic atrophy is related to body mass index and age at onset in amyotrophic lateral sclerosis.2017. Neurol Neurosurg Psychiatry;0:1-9 